\title{
O PRINCÍPIO DA ESSENCIALIDADE NA TRIBUTAÇÃO
}

\author{
Rosane Beatriz Jachimovski Danilevicz ${ }^{1}$
}

\section{RESUMO}

O Estado brasileiro constitui-se em um Estado Democrático de Direito e tem por fundamento a soberania, a cidadania, a dignidade da pessoa humana, dentre outros. A dignidade humana identifica um espaço de integridade a ser assegurado a todas as pessoas por sua existência e seu conteúdo está associado aos direitos fundamentais e ao mínimo existencial. No âmbito da tributação, a proteção ao mínimo existencial se manifesta na essencialidade de certos produtos. A essencialidade consiste num princípio de política fiscal, instrumento de distribuição de renda e justiça que se realiza na tributação por meio da seletividade.

Descritores: Tributação. Igualdade. Capacidade contributiva. Mínimo existencial. Dignidade humana. Essencialidade.

\section{INTRODUÇÃO}

O presente artigo tem por objeto analisar e identificar os aspectos da essencialidade como um princípio constitucional da tributação. Cumpre registrar que a essencialidade é um tema que não tem sido muito examinado pela doutrina, pois

1 Mestre em Instituições do Direito do Estado pela PUCRS. Especialista em Direito Público pela ULBRA. Professora das Faculdades Integradas São Judas Tadeu. Advogada. Currículo: http://buscatextual.cnpq.br/buscatextual/visualizacv.jsp?id=E9231753. Endereço profissonal: Rua Quintino Bocaiúva, 554/203, Moinhos de Vento, Porto Alegre, RS, Brasil, CEP 90.440-050. Endereço eletrônico: rdanilevicz@yahoo.com . 
essa lhe tem dado pouca atenção, limitando-se a afirmar que consiste numa diretriz à seletividade, bem como poucas questões são levadas ao Poder Judiciário.

As razões que justificam o presente estudo são encontradas na atualidade e na relevância do tema, na medida em que a exoneração da carga tributária sobre as necessidades essenciais na tributação sobre o consumo pode ser satisfeita pela graduação das alíquotas de acordo com a essencialidade dos produtos, mercadorias e serviços.

\section{ELEMENTOS RELEVANTES PARA ANÁLISE DO PRINCÍPIO DA ESSENCIALIDADE}

Além da Noção de Princípios e Regras, serão abordados neste artigo: o Princípio da Igualdade, o Princípio da Capacidade Contributiva e o Mínimo Existencial.

\subsection{Noção de Princípios e Regras}

O Sistema Constitucional Tributário é formado por um conjunto de normas jurídicas - princípios e regras - que atuam de forma coordenada e lógica para que o Estado desenvolva meios para obtenção dos recursos necessários ao cumprimento de suas finalidades e atendimento das necessidades da coletividade, os quais se consubstanciam na tributação.

Quanto aos princípios, é importante destacar que estão vinculados a valores, porém com eles não se confundem. No direito tributário, ainda que o orçamento e a tributação não decorram de valores, estão em um campo axiológico marcado pelos valores éticos e jurídicos que devem estar contidos nas políticas públicas.

Ricardo Lobo Torres observa que os princípios, assim como os valores, têm por características a generalidade e a abstração, porém com menor intensidade. Os valores são ideias abstratas, supraconstitucionais, enquanto os princípios se encontram entre os valores e as regras, demonstrando em parte a generalidade e a abstração dos valores e a concretude das regras. Os princípios podem estar presentes nas disposições constitucionais como uma concretização dos valores. Porém, se estiverem ausentes daquele texto, não perdem suas características. De modo que os princípios e as regras se concretizam a partir dos valores, em processo de legitimação por intermédio da ponderação, razoabilidade, igual-dade (Torres, 2005, p. 194-195).

Enquanto os princípios expressam um dever, os valores expressam um critério de valoração. Por isso os valores não possuem eficácia jurídica direta e se concretizam na ordem jurídica por meio dos princípios.

No caminho da formulação do conceito de princípio, Riccardo Guas- 
tini afirma que não é fácil individualizar quais propriedades deve ter uma norma para merecer o nome de "princípio”. Todavia, a "grosso modo”, diz que os princípios caracterizam-se "pelo lugar que ocupam no ordenamento jurídico como um todo e/ou em algum setor específico." São as normas que aparecem como "caracterizantes" do ordenamento ou de uma parte sua. "Seriam enunciados dotados de um significado muito elástico e/ou indeterminado". Normalmente, os princípios são normas muito vagas. Um princípio é vago porque "não possui um campo exato de aplicação" ou "porque possui um conteúdo teleológico ou programático”, exprimindo um valor ou recomendando um fim, ou "a realização de um programa" sem "estabelecer os meios que devem ser empregados”. E relativamente a outras normas, os princípios se caracterizam em razão de sua generalidade (Guastini, 2005, p. 186-190).

Conforme José Canotilho, os princípios ou os valores por eles revelados, de liberdade, igualdade, dignidade são essenciais ao sistema jurídico (Canotilho, 2003, p. 1163). Nessa linha, os princípios são normas presentes na Constituição e nos fundamentos de regras jurídicas, ou seja, são proposições básicas que fundamentam o ordenamento jurídico. A partir da sua positivação e constitucionalização, os princípios ganharam normatividade, passando a impor uma aplicação obrigatória, devendo a lei suprir e esclarecer os seus mandamentos.

Vale dizer que os princípios jurídicos são ideias fundantes dos sistemas jurídicos constitucionais e eficazes instrumentos de interpretação e integração do Direito. No dizer de Ricardo Lobo Torres, "os princípios são enunciados genéricos que concretizam valores morais e conduzem à elaboração, interpretação e aplicação das regras jurídicas” (Torres, 2005, p. 275).

Nesse prisma, Juarez Freitas entende por princípios fundamentais

os critérios ou as diretrizes basilares do sistema jurídico, que se traduzem como disposições hierarquicamente superiores, do ponto de vista axiológico, às normas estritas (regras) e os próprios valores (mais genéricos e indeterminados), sendo linhas mestras de acordo com as quais guiarse-á o intérprete quando se defrontar com as antinomias jurídicas (Freitas, 2004, p. 56).

Tais orientações revelam que os princípios são instrumentos valiosos para uma adequada interpretação constitucional. A par disso, os princípios também constituem subsídios importantes para fundamentar as decisões judiciais, bem como critérios para o processo de interpretação e aplicação do Direito, uma vez que exige do operador jurídico a observância obrigatória aos mesmos. 
Ultrapassada a análise relativa aos princípios, cumpre apresentar a distinção entre princípios e regras, tema crucial para o direito público, uma vez que as disposições constitucionais sobre tributação necessitam de regras reguladoras da criação, fiscalização e arrecadação das prestações de natureza tributária.

A distinção entre princípios e regras é um tema polêmico, haja vista serem vários os critérios para estabelecer as diferenças. Diante disso, cabe destacar que o presente estudo não tem a pretensão de esgotar os doutrinadores que tratam do tema, mas apenas examinar algumas concepções sustentadas.

Ronald Dworkin estabeleceu a diferença estrutural entre princípios e regras a partir de critérios classificatórios. Em sua concepção, uma regra vale ou não vale. Trata-se de um tudo ou nada, ou seja, ocorrendo a hipótese descrita na regra, ela será válida, devendo, portanto, ser aplicada. Em havendo colisão de regras, uma delas deve ser considerada inválida. Quanto aos princípios, o autor entende que admitem uma aplicação mais ou menos ampla e de acordo com as possibilidades normativas e fáticas, uma vez que contêm fundamentos para a decisão, os quais devem ser conjugados com fundamentos de outros princípios. Sustenta, ainda, que os princípios possuem uma dimensão de peso ou importância que falta às regras (Dworkin, 1993, p. 74-77).
Robert Alexy tem por ponto decisivo para a distinção entre regras e princípios, o fato de os princípios serem normas que ordenam a realização de algo na maior medida possível, dentro das possibilidades jurídicas e fáticas. De modo que os princípios são comandos de otimização aplicáveis em vários graus, enquanto as regras contêm determinações. O conflito entre regras se resolve pela introdução, em uma das regras, de uma cláusula de exceção que elimina o conflito ou pela declaração de invalidade de uma das regras. A colisão de princípios se resolve com a ponderação entre os princípios colidentes, de modo que um prevalecerá sobre o outro. O que não significa invalidar o princípio desprezado nem implica a inclusão de uma cláusula de exceção. Assim, os princípios têm apenas uma dimensão de peso, não determinando as consequências normativas como ocorre com as regras (Alexy, 2001).

Dentre os nossos doutrinadores, destaca-se, inicialmente, Juarez Freitas, para quem os princípios diferenciam-se das regras, não por sua generalidade, mas por sua qualidade argumentativa superior. Por isso, em caso de colisão, a interpretação deve ser conforme os princípios. A supremacia da "fundamentalidade" na colisão de princípio ou no conflito de regras faz com que um princípio prepondere e não uma regra. Para o autor, as regras são preceitos menos amplos 
e axiologicamente inferiores. Servem para harmonizar e dar concretude aos princípios fundamentais. Por isso, não podem ser aplicadas automaticamente, porquanto "a compreensão das regras implica uma simultânea [...] aplicação dos princípios em conexão com as várias frações do ordenamento" (Freitas, 2004, p. 56-57). Humberto Ávila opta por posição diversa, sustentando que a solução do conflito entre regras e princípios depende do nível hierárquico das espécies normativas. Desse modo, em sendo de hierarquia diferente, tanto se tratando de um princípio ou uma regra, prevalecerá a norma de hierarquia superior. Já o conflito entre um princípio constitucional e uma regra infraconstitucional deve ser solucionado com a prevalência do princípio. O conflito entre uma regra constitucional e um princípio infraconstitucional será resolvido com a prevalência da regra. Ocorrendo o conflito entre um princípio e uma regra constitucionais, deve ser dada prevalência à regra, caso não se trate, apenas, de uma extensão ou restrição teleológica em âmbitos permitidos do Direito (Ávila, 2004b, p. 85).

Humberto Ávila entende que as regras e os princípios diferenciam-se quanto ao modo como prescrevem o comportamento. Assim, as regras qualificam-se como normas imediatamente descritivas da conduta a ser adotada, tendo em vista que estabelecem obrigações, permissões ou proibições, enquanto os princípios sãonormas imediatamentefinalísticas, pois determinam um estado de coisas e necessitam da adoção de determinados comportamentos para sua promoção. Sustentando que as regras também podem ser diferenciadas dos princípios quanto à justificação que exigem para a adoção de uma determinada interpretação e aplicação, o autor afasta o modo do tudo ou nada, e afirma que, para a interpretação e aplicação das regras, é necessária uma análise da correspondência entre os fatos e as disposições da norma. Já os princípios reclamam uma análise entre o estado de coisas a ser promovido e a conduta adotada. Segundo o autor, as regras ainda podem ser diferenciadas dos princípios quanto ao modo como contribuem para a decisão. Desse modo, os princípios são normas com pretensão de complementaridade $e$ de parcialidade, pois apenas estabelecem diretrizes valorativas a serem alcançadas, não descrevendo o comportamento adequado para a tomada de decisão, de modo que não geram uma solução específica, todavia, contribuem para a chegada a uma solução. Já as regras são normas preliminarmente decisivas $e$ abarcantes, uma vez que abrangem os vários aspectos relevantes para a tomada de decisão a fim de buscar uma determinada solução ao caso (Ávila, 2004b, p. 63-69).

Na visão de Eros Grau, a generalidade de uma regra é diversa 
da generalidade de um princípio, porquanto a regra é estabelecida para um indeterminado número de atos ou fatos, enquanto os princípios comportam indefinidas aplicações. É no momento da interpretação/ aplicação que surge a diferença entre regra e princípio. Assim, no curso do processo interpretativo é que o intérprete decidirá se existe ou não conflito entre regras ou colisão entre princípios. Ainda, os princípios atuam como mecanismos de controle da produção de normas-regras, bem como podem ser a medida do controle externo da produção de normas. Além do que cabe ao intérprete a escolha do princípio a partir da ponderação do seu próprio conteúdo, enquanto a declaração da validade de cada regra depende do exame de critérios formais externos (Grau, 2005, p. 183).

Consoante aponta Paulo Caliendo, não há um critério hermenêutico que estabeleça anterior à experiência "a prevalência dos princípios sobre as regras ou vice-versa”. Tal raciocínio deve ser empregado "para os casos em que princípios e regras possuam mesma hierarquia (constitucional ou infraconstitucional)", uma vez que, entre normas de hierarquia diversa, os "fundamentos de validade” podem ser alcançados "nos critérios sobre norma superior e inferior". Somente a verificação do caso concreto pode determinar se deverá prevalecer o princípio ou a regra (Caliendo, 2006, p. 132).

Vários são os argumentos que demonstram a inexistência de um critério hermenêutico que estabeleça em princípio a prevalência de princípios ou regras. Além do argumento de que, a partir de uma interpretação tópico-sistemática do caso concreto, é possível comprovar as conexões lógico-axiológicas que indicarão a melhor solução possível para o caso (Caliendo, 2006, p. 151), há o argumento decorrente do fato de os princípios e regras possuírem natureza lógico-sintática diversa.

Diante de tudo o que foi exposto, depreende-se que os princípios contêm uma maior carga valorativa, um fundamento ético e indicam uma determinada direção a seguir. São aplicados a um número indeterminado de situações mediante ponderação, pois não descrevem as condições necessárias para sua utilização. A validade dos princípios resulta do seu próprio conteúdo, que, em maior ou menor medida, são universais, absolutos, objetivos e permanentes. Possuem uma aplicação explicadora e justificadora em relação às regras e sintetizam uma grande quantidade de informação de um setor ou de todo o ordenamento jurídico, conferindolhe unidade e ordenação. Quando em colisão nenhum princípio é excluído, cabe ao intérprete hierarquizá-los axiologicamente.

Por sua vez, as regras se referem ao mundo concreto e são normas descritivas que estabelecem obrigações, proibições ou permissões 
por meio de condutas pré- ciação e das finalidades justificadoras estabelecidas. Decorrem de outras da diferenciação” (Ávila, 2004a, p. regras ou até mesmo de princípios. Garantem a previsibilidade do sistema, pois seu comando é objetivo, não dando margem a outras incidências, de modo que sua aplicação se dá sob a forma da subsunção, ou seja, enquadram-se os fatos na previsão abstrata e produz-se uma conclusão. Em havendo conflito entre duas regras, somente uma será válida e irá prevalecer.

Tais considerações sobre princípios e regras são relevantes, tendo em vista que estabelecem e influenciam diretamente na unidade interna constitucional, determinando os vínculos relacionais que se tem entre essas normas.

\subsection{O Princípio da Igualdade}

A igualdade é um princípio que permeia praticamente todo o nosso Sistema Constitucional. Humberto Ávila refere que a igualdade possui uma "dimensão normativa proponderante de princípio", pois estabelece um estado ideal que deve ser perseguido no exercício das competências atri-buídas aos entes públicos. Porém, tem também um sentido "indireto de regra" ao descrever "o comportamento a ser adotado pelo Poder Público” diante de "situações equivalentes" e de postulado ao exigir à aplicação "a consideração e avaliação dos sujeitos envolvidos, dos critérios de diferen334-335).

A igualdade perante a lei é a primeira reconhecida em nossa Constituição Federal, ou seja, a igualdade formal consagrada no caput do art. 50. Trata-se da obrigatoriedade de aplicação das normas jurídicas gerais aos casos concretos, exigindo uniformidade na sua aplicação.

No tocante à igualdade material, é sabido que ela não existe entre os indivíduos, seja no aspecto social, biológico ou psicológico, bem como não irá acontecer, porquanto a desigualdade entre os indivíduos é inerente à natureza humana. Contudo, as desigualdades sociais podem ser reduzidas por meio do princípio da igualdade material, cabendo ao Estado a promoção de oportunidades através de políticas públicas e leis que atendam às necessidades dos indivíduos menos favorecidos, de modo a compensar eventuais desigualdades.

O princípio da igualdade consiste na determinação de um tratamento idêntico pela lei, tratando desigualmente os casos desiguais segundo critérios abrigados pelo sistema jurídico.

Em sendo as pessoas desiguais, jamais o tratamento poderá ser o mesmo. Logo, para a aplicação do princípio da igualdade, é necessário um tratamento desigual que, de algum modo, adequar-se-á às peculiaridades decorrentes da desigualdade. 
Essa é a razão pela qual Misabel de Abreu Derzi, ao atualizar a obra de Aliomar Baleeiro, refere que "o princípio da igualdade formal é uma norma que impõe o mesmo tratamento aos iguais e outro aos desiguais", presumindo a diferença "relativa" entre as pessoas, a viabilidade de sua comparação conforme um determinado critério e o caráter axiológico deste (Baleeiro, 2005, p. 527). Consiste, então, o princípio da igualdade na determinação de um tratamento idêntico pela lei, tratando desigualmente os casos desiguais segundo critérios abrigados pelo sistema jurídico.

A concretização do princípio da igualdade depende do critério discriminatório, pois ele mesmo nada diz quanto aos bens ou aos fins de que serve de igualdade para diferenciar as pessoas. A diferenciação somente importa quando lhe é agregada uma finalidade, de modo que as pessoas são iguais ou diferentes segundo um mesmo critério. Portanto, a aplicação da igualdade depende de um critério diferenciador e de um fim a ser alcançado (Ávila, 2004b, p. 101-102).

Desse modo, para a busca da igualdade, faz-se necessária a escolha de um critério diferenciador justificante do tratamento desigual, tendo em vista que os desiguais devem ser tratados desigualmente, segundo a finalidade perseguida pelo ordenamen- to jurídico, sob pena de cometimento de discriminação arbitrária.

Pode-se afirmar, então, que é preciso verificar como alguns são iguais ou não, bem como estabelecer qual o critério a ser adotado para a diferenciação para que sejam tratados igualmente os iguais e desigualmente os desiguais.

Consoante o disposto no artigo $5^{\circ}$ da CF, todos têm direito ao mesmo tratamento, de sorte que "a lei tributária deverá ser uniformemente aplicada". Sendo importante "que a diferenciação normativa dos sujeitos que se encontrarem" na mesma situação ocorra de maneira invariável, "sem a introdução de exceções ou privilégios para determinadas pessoas” (Ávila, 2005, p. 414).

Nesse contexto é que o princípio da igualdade tributária consiste em uma limitação ao poder de tributar consagrada no artigo 150, II, da Constituição Federal, que dispõe:

Art. 150. Sem prejuízo de outras garantias asseguradas ao contribuinte, é vedado à União, aos Estados, ao Distrito Federal e aos Municípios: [...].

II - instituir tratamento desigual entre contribuintes que se encontrem em situação equivalente, proibida qualquer distinção em razão de ocupação profissional ou função por eles exercida, independentemente da denominação jurídica dos rendimentos, títulos ou direitos (Brasil, 2008). 
Percebe-se que o princípio da igualdade na tributação acarreta a proibição de arbitrariedades ou excessos, à medida que veda a desigualdade entre indivíduos que se encontrem nas mesmas condições. De modo que é vedado à lei tributária instituir privilégios ou gravames que não sejam uniformes aos contribuintes em igualdade de condições.

O princípio da igualdade ante a lei tributária, além de ser igual para todos que estiverem na mesma situação jurídica, requer que o tributo instituído por lei editada pelo Poder competente não atinja apenas alguns contribuintes, deixando a salvo outros que, comprovadamente, se encontram nas mesmas condições. Diante disso, como aferir a igualdade entre os contribuintes? Quem são os contribuintes que se encontram em situação equivalente e merecem tratamento isonômico?

É sabido que “o princípio da igualdade admite a comparabilidade entre indivíduos distintos”, para reunilos conforme "suas semelhanças e diferenças” e, por isso, a igualdade somente é "aferível por meio de um critério de comparação” (Baleeiro, 2005, p. 378-379).

Um dos mais importantes modos de aferição da igualdade é a capacidade contributiva, porquanto se todos são iguais perante a lei, todos serão tributados, sendo o critério de igualdade/desigualdade os recursos financeiros de cada um.

\subsection{O Princípio da Capacidade Contributiva}

Tendo em vista que os encargos públicos são repartidos entre os membros da coletividade, o pagamento de tributos é um dever fundamental. Em sendo assim, o fundamento para a tributação não é a contraprestação do serviço público, mas o concurso de todos para as despesas do Estado.

Ainda que o poder de tributar seja uma das manifestações do poder do Estado, é certo que tal poder não é livre nem pode ser arbitrário. Por essa razão o Estado somente pode atuar dentro do Direito e em observância às limitações impostas, dentre as quais se encontra a capacidade contributiva do indivíduo.

A capacidade contributiva está associada à capacidade econômica do indivíduo em contribuir para a manutenção do Estado e consiste no critério de diferenciação aplicado à igualdade no âmbito do Direito Tributário, haja vista servir de medida para a distribuição dos encargos estatais, igualando ou desigualando os contribuintes a partir das possibilidades econômicas de cada um.

O princípio da capacidade contributiva está previsto no § $1^{\circ}$, do artigo 145 , da Constituição 
Federal. Destina-se a informar a discricionariedade do legislador, condicionando-o a adaptar a tributação, de maneira tal que as incidências não sejam excessivas nem resultantes de presunções, resguardando o mínimo existencial e obrigando o sistema de tributação a respeitar a capacidade econômica dos contribuintes.

Desse modo, o princípio da capacidade contributiva, além de servir de instrumento para alcançar recursos de quem pode mais, serve para limitar a discricionariedade do legislador, abreviando imposições exageradas, com fins confiscatórios e onerosos do mínimo existencial.

A força normativa do princípio da capacidade contributiva resulta da conjugação dos fundamentos da República contidos no art. $1^{0}$ dignidade da pessoa humana, os valores sociais do trabalho e da livre iniciativa - e de seus objetivos fundamentais previstos no caput do art. $3^{\circ}$ - sociedade livre, justa e solidária. Combinado, ainda, com o art. 170 que preconiza os valores e os princípios que compõem a ordem econômica.

Com a observância do princípio da capacidade contributiva, o tratamento tributário será justo quando o legislador considerar as disparidades entre os contribuintes, tratando de modo desigual os desiguais cuja imposição tributária considere a capacidade contributiva de cada um individualmente. Desse modo, a tributação será justa quando for adequada à capacidade econômica do contribuinte de suportá-la.

É precisamentenesse contexto, que o princípio da capacidade contributiva é o modo de operacionalização da justiça fiscal defendida pela Constituição. Através dele é possível realizar a igualdade, que somente tem sentido quando é possível crer que as pessoas com rendas diferentes possam ser tributadas de modo diferente.

Por isso, quando se diz que "é justo cobrar impostos na proporção dos beneficiários" não significa que cada um deve pagar determinada quantia na medida dos benefícios recebidos, "mas sim que cada pessoa deve ser onerada em termos reais na proporção dos benefícios recebidos" (Murphy; Nagel, 2005, p. 24).

A capacidade contributiva inserida no preceito constitucional exige que toda imposição tributária se justifique em face de manifestações reais e concretas de riqueza. Isto é, onde não houver riqueza não há capacidade contributiva.

Assim, se de um lado os indivíduos têm a obrigação de contribuir para as despesas públicas decorrentes do dever de solidariedade, de outro, o princípio da capacidade contributiva restringe esse dever e o poder de imposição do Estado.

Diante disso, para a caracterização da capacidade contributiva não é suficiente dizer que os fatos 
econômicos expressam capacidade contributiva, pois é necessário que se indique quais fatos. Nessa seara, a renda total, o patrimônio, o consumo ou, até mesmo, a combinação desses, podem ser fatos reveladores de capacidade contributiva.

Assim como os economistas, a doutrina jurídica costuma comparar a capacidade contributiva com a capacidade econômica. A capacidade contributiva teria início quando afastadas todas as despesas necessárias à vida digna do contribuinte, bem como de sua família. Por sua vez, a capacidade econômica consiste no montante total da renda econômica.

O modo mais basilar de compreender a capacidade econômica é apreciá-la de maneira subjetiva, atendendo as situações pessoais dos titulares de riquezas, uma vez que nem todos que manifestam igual capacidade econômica oferecem a mesma capacidade para contribuir com o Estado.

Assim, a capacidade contributiva se manifesta na possibilidade de o indivíduo colaborar para a manutenção do Estado somente a partir do momento em que estiverem supridas as condições mínimas e indispensáveis a uma sobrevivência digna.

O princípio da capacidade contributiva melhor se aplica aos impostos diretos. Nos impostos indiretos a capacidade contributiva nem sempre acontece, uma vez que a carga econômica do imposto não é suportada pelo produtor, industrial ou comerciante que realiza a operação, mas pelo consumidor final, cuja mensuração da capacidade econômica é difícil. Isso ocorre por não ser possível, antecipadamente, conhecer quem será e quais as condições econômicas do destinatário final do produto, mercadoria ou serviço.

Em razão disso, o constituinte estabeleceu a seletividade das alíquotas como forma de minimizar as consequências da transferência do ônus tributário e aplicar, ainda que minimamente, o princípio da capacidade contributiva àqueles que acabam pagando o tributo inserido no preço do produto, mercadoria ou serviço.

\subsection{O Mínimo Existencial}

Como observado, o princípio da capacidade contributiva estabelece a margem econômica da riqueza que pode ser tributada e a capacidade econômica se manifesta na possibilidade do indivíduo em colaborar para a manutenção do Estado. Ocorre que tal colaboração somente se realiza a partir do momento em que estiverem supridas as condições mínimas e indispensáveis à sobrevivência do indivíduo com dignidade.

Razão pela qual Alfredo Augusto Becker advertira que é preciso que o legislador escolha "para a composição da hipótese de incidência das regras jurídicas tributárias, fatos que sejam 
signos presuntivos de renda ou capital acima do mínimo indispensável” (Becker, 1972, p. 444-445).

Em sendo assim, a renda tributável não tem início com a mera obtenção de recursos, porque deve ser protegida da tributação uma parcela da renda destinada a suprir as necessidades básicas que garantam as condições mínimas de existência digna do indivíduo e de sua família.

Isso ocorre porque o Estado não pode privar o indivíduo de sua própria renda até o limite do mínimo necessário para sua existência.

O artigo 145 da Constituição Federal determina que os tributos sejam graduados segundo a capacidade econômica do contribuinte (Brasil, 2008). Assim, a tributação está limitada à capacidade contributiva do indivíduo determinada a partir de sua capacidade econômica, que deve ser entendida como aquela parcela excedente do mínimo existencial. De modo que a proteção ao mínimo existencial é um elemento indispensável na formação da capacidade contributiva.

Por mínimo existencial entende-se aquela parcela da renda que se destina a solver as necessidades básicas do indivíduo e o núcleo familiar dependente, tais como: alimentação, vestuário, educação, trabalho, saúde, lazer, dentre outras prerrogativas consagradas na Constituição Federal e que possibilitam a manutenção da dignidade dos indivíduos.

Apesar de o mínimo existencial ser um direito que não se encontra ex- pressamente previsto em nossa atual Constituição Federal, está implicitamente compreendido pelo princípio fundamental da dignidade da pessoa humana e pelos objetivos fundamentais da República: erradicação da pobreza, marginalização e redução das desigualdades.

O princípio da dignidade da pessoa humana está previsto no inciso III, do artigo $1^{\circ}$ da Constituição Federal (Brasil, 2008) e se encontra inserido no fim primeiro de nosso Estado, constituindo-se no sustentáculo dos direitos fundamentais que são indispensáveis e necessários para assegurar ao ser humano uma existência digna e o mínimo existencial deve ser considerado como uma subespécie desses direitos.

Do modo como a dignidade humana foi constitucionalmente prevista, depreende-se sua valorização no sentido de que as atenções do Estado devem ser dirigidas elevando o homem ao mais alto grau de importância.

Por isso, Humberto Ávila assevera que a dignidade humana "possui uma dimensão preponderante de sobreprincípio", tendo em vista que determina ao Poder Público "o dever de buscar um ideal de importância e de valoração para o homem cidadão”. Sua importância "na ordem constitucional" é imensa, refletindo até mesmo na "atividade hermenêutica", na medida em que essa deverá sempre colocar o homem no centro de importância e de valoração (Ávila, 2004a, 
p. 319). Segundo o autor, a dignidade humana tem eficácia indireta em questões tributárias

como as relações obrigacionais tributárias possuem efeitos patrimoniais decorrentes da apropriação de meios de pagamento e efeitos comportamentais juntos ou separados dos encargos tributários, elas atingem a esfera privada e mantêm relação necessária com a liberdade e a propriedade, cuja disponibilidade é afetada. $\mathrm{O}$ direito à vida não é violado pelas leis tributárias, desde que se mantenha disponível um mínimo em liberdade e em propriedade.

[...].

A preservação do direito à vida e à dignidade e da garantia dos direitos fundamentais de liberdade alicerçam não apenas uma pretensão de defesa contra restrições injustificadas do Estado nesses bens jurídicos, mas exigem do Estado medidas efetivas para a proteção desses bens. O aspecto tributário dessa tarefa é a proibição de tributar o mínimo existencial do sujeito passivo (Ávila, 2004a, p. 318-319).

Assim, em face da dignidade da pessoa humana, as limitações ao poder de tributar não podem consistir apenas na igualdade tributária, tendo em vista que o seu resguardo implica a observância da capacidade contributiva e do mínimo existencial, indispensável à subsistência humana.

No que concerne ao mínimo existencial, os direitos sociais - a educação, a saúde, a moradia, a previdência social, o salário mínimo dos trabalhadores - vinculam parte daquilo que se considera necessário para ser atendido pelo mínimo existencial, isto é, as prestações que devam ser acolhidas por esse mínimo e que sirvam de referência ao Poder Público.

Importa considerar que o mínimo existencial não tem um conteúdo específico e mensurável, abrange muito mais aspectos de qualidade do que de quantidade, bem como é variável, tendo em vista que, além das necessidades humanas serem infinitas e também variadas, constantemente surgem novas necessidades, bem como as diversidades regionais contribuem para tanto. Essa é a razão pela qual Ingo Wolfgang Sarlet salienta que

já não se pode negligenciar a circunstância de que o valor necessário para a garantia das condições mínimas de existência evidentemente estará sujeito às flutuações, não apenas na esfera econômica e financeira, mas também das expectativas e necessidades vigentes (Sarlet, 2007, p. 49).

Em sendo assim, o direito ao mínimo existencial impede o exercício do poder de tributar, em face da situação econômica do indivíduo, bem como se refere à prestação de serviços públicos. Isto é, o mínimo existencial não se resume ao direito de condições materiais mínimas a 
uma vida digna, mas, também, ao direito de obtenção da promoção e facilitação estatal ao crescimento econômico e social, que no Direito Tributário implica a eliminação de obstáculos impeditivos da realização desse mínimo.

Assim, a realização do indivíduo como ser livre exige a atenção a requisitos indispensáveis, sem os quais não é possível alcançar a plenitude que lhe é assegurada pela Constituição Federal. Daí que no âmbito da esfera patrimonial do indivíduo deve ser garantido um mínimo de condições de existência que permitam seu desenvolvimento.

De outra parte, vale dizer, também, que o mínimo existencial deve ser observado tanto na tributação dos impostos diretos, como na tributação dos impostos indiretos. Uma forma de proteger o mínimo existencial da tributação dos impostos indiretos ocorre pela aplicação da seletividade, onde os impostos incidem com alíquotas mais elevadas, na razão inversa da essencialidade do produto, mercadoria ou serviço.

\section{O PRINCÍPIO DA ESSENCIALIDADE}

É por meio do princípio da seletividade que se viabiliza, ainda que minimamente, a observância da capacidade contributiva nos impostos indiretos. Tal princípio determina que o legislador gradue a incidência tributária sobre produtos, mercadorias ou serviços de acordo com sua essencialidade, de modo que quanto maior a importância social do bem consumido, menor será a carga tributária incidente sobre eles.

A seletividade visa isentar ou privilegiar com alíquotas mais baixas os bens e serviços essenciais à população. De modo que o imposto seletivo é aquele que onera diferentemente os bens sobre o qual incide, escolhendo-se esses bens em razão de sua essencialidade a uma vida digna.

O que ocorre, através da aplicação da seletividade, é uma presunção de existência de riqueza, reveladora do potencial capacidade contributiva do consumidor. De modo que a sua aplicação apresentará distorções quando a parcela mais favorecida da população também adquire produtos, mercadorias ou serviços de primeira necessidade, com reduzida ou nenhuma tributação, quando, na realidade, teria condições de suportar o ônus tributário.

De igual modo, o indivíduo economicamente menos favorecido, ao adquirir um produto, mercadoria ou serviço considerado supérfluo, arcará com a mesma carga tributária existente para os economicamente mais favorecidos, porém, o ônus suportado em relação à sua receita será proporcionalmente mais elevado. 
Nos impostos indiretos, a exoneração da carga tributária sobre as necessidades essenciais pode ser satisfeita pela isenção de produtos, mercadorias e serviços indispensáveis ou pela graduação da alíquota. É justamente nesse contexto que a essencialidade dos produtos, mercadorias e serviços se realiza na tributação.

A observância da essencialidade serve para preservação do mínimo existencial e, por conseguinte, atenção ao princípio da dignidade humana, na medida em que estabelece que quanto mais essencial for o produto, mercadoria ou serviço para a coletividade, menor deverá ser a sua alíquota, bem como quanto menos essencial, maior deverá ser a alíquota aplicável.

A discriminação entre as coisas essenciais e as supérfluas, ou ainda, a graduação do que é mais ou menos essencial, visa atender o dever de tributação diferenciada daquilo que é necessário e o que não é.

Também pode resultar da seletividade em função da essencialidade, que determinado produto, mercadoria ou serviço tributado de maneira mais favorável ou menos gravosa, seja consumido preponderantemente por uma classe de pessoas menos aquinhoadas financeiramente, tendo em vista que o consumo de produtos supérfluos e, por via de consequência, maior tributados, depende apenas da vontade de cada um.

Por isso a essencialidade não depende da capacidade contributiva do consumidor de produtos, mercadorias ou serviços, uma vez que ela é objetiva e igual para todos.

A essencialidade dos produtos, mercadorias e serviços foi um meio adotado pelo constituinte para a operacionalização da seletividade, diz a Constituição Federal

Art. 153. Compete à União instituir impostos sobre:

[...];

IV - produtos industrializados;

[...].

$\S 3^{\circ}$ - O imposto previsto no inciso IV:

I - será seletivo, em função da essencialidade do produto (Brasil, 2008).

Desse modo, o legislador ordinário ao instituir concretamente o Imposto sobre Produtos Industrializados - IPI - deve considerar que haverá de ser seletivo em função da essencialidade do produto.

Quanto ao imposto sobre operações relativas à circulação de mercadorias e serviços - ICMS (Imposto sobre Circulação de Mercadorias e Prestação de Serviços) - a Constituição Federal estabelece:

Art. 155. Compete aos Estados e ao Distrito Federal instituir impostos sobre:

[...];

II - operações relativas à circulação de mercadorias e sobre prestações de serviços de transporte interestadual e intermunicipal e de comunicação, 
ainda que as operações e as prestações se iniciem no exterior;

[...].

$\S 2 .^{\circ} \mathrm{O}$ imposto previsto no inciso II atenderá ao seguinte:

[...];

III - poderá ser seletivo, em função da essencialidade das mercadorias e dos serviços (Brasil, 2008).

De acordo com o texto constitucional quando o legislador ordinário instituir concretamente o ICMS deverá considerar que o imposto poderá ser seletivo, em função da essencialidade das mercadorias e dos serviços. Importa registrar que parte da doutrina tem entendido que a expressão “poderá ser seletivo” para o ICMS equivale a um dever. ${ }^{2}$
É sabido que o IPI e o ICMS são impostos que recaem sobre a produção e o consumo e, portanto, comportam a transferência do ônus financeiro, por isso a sua adequação à capacidade contributiva do consumidor não é muito fácil, como nem sempre será possível obter resultados muito justos.

De fato, os gastos realizados com consumo de bens e serviços não revelam as características de pessoalidade dos contribuintes, como ocorre nos impostos diretos onde melhor se verifica a capacidade contributiva dos contribuintes, uma vez que neles são consideradas as particularidades deles.

2 Roque Antônio Carrazza, lembrando que o ICMS serve de "instrumento de extrafiscalidade", sustenta que a seletividade é obrigatória tanto no IPI como no ICMS. Porquanto o termo "poderá", constante do art. $155, \S 2^{\circ}$, III da CF significa “deverá”. Não se trata de "uma mera faculdade do legislador”, mas sim de uma norma de “observância obrigatória”. A Constituição Federal, quando confere um poder ao ente estatal, está lhe impondo um dever. Por isso o princípio da seletividade "pode e deve ser” empregado "como instrumento de ordenação político-econômica, estimulando a prática de operações ou prestações havidas por úteis e convenientes para o País”, bem como “onerando outras que não atendam tão de perto ao interesse nacional”. Razão pela qual é possível aplicar "em algumas operações com produtos supérfluos, a alíquota” de 25\% "e, em outras, com produtos essenciais, as alíquotas baixam para 18\%, 17\% e, até 12\% e 9\%” (Carraza, 2006, p. 374-375). Hugo de Brito Machado Segundo, analisando sob outro aspecto, observa que "a Constituição não asseverou que o imposto poderá ser seletivo, e que essa seletividade poderá ser de acordo com a essencialidade das mercadorias e serviço”. Se fosse esse o sentido do dispositivo constitucional, "tratar-seia de norma tola, porquanto todo o imposto pode, em princípio, ser seletivo, de acordo com qualquer critério, inclusive a essencialidade do bem tributado". Na realidade, o sentido da expressão quer dizer que o ICMS poderá ser seletivo. Se for seletivo, a “seletividade deverá ocorrer de acordo com a essencialidade das mercadorias e dos serviços” (Machado Segundo, 2000, p. 72). 
A realidade revela que o imposto incidente sobre o consumo tem efeito regressivo, isto é, quem possui menor poder aquisitivo, proporcionalmente à sua renda, termina por pagar mais imposto do que aquele com maior poder aquisitivo.

Anote-se que a Constituição Federal não revela quais produtos, mercadorias ou serviços devem ser considerados essenciais. Todavia, a partir de uma interpretação sistemática do texto constitucional, pode-se afirmar ser essencial todo o produto, mercadoria e serviço que atenda às necessidades indispensáveis, tais como: saúde, alimentação, moradia, vestuário, trabalho, cultura, lazer, serviços de telecomunicação, energia elétrica etc.

Por outro lado, é intuitivo que a Constituição Federal quando refere a essencialidade emprega um termo que permite uma variada graduação, sem, no entanto, delimitá-la. Desse modo, diante da variedade de produtos e serviços existentes, há aqueles que serão considerados mais ou menos essenciais à vida humana.

Num primeiro momento, o conceito de essencialidade enseja o entendimento de que estaria restrito apenas àqueles bens e serviços de primeira necessidade, ou seja, àqueles indispensáveis à sobrevivência biológica do indivíduo. Contudo, é preciso ampliar tal conceito de modo que se assegure a sobrevida biológica e social da pessoa humana com um mínimo de dignidade.

É precisamente nesse contexto que Henry Tilbery constata que o sentido da essencialidade alcança aquelas necessidades que são indispensáveis por natureza, como também "aqueles bens que, conforme a opinião estabelecida de decência, não deviam faltar" aos mais humildes. Assim, "o conceito da essencialidade vinculase a um mínimo de vida não devendo ninguém ficar abaixo de tal padrão" (Tilbery, 1974, p. 326).

Em vista disso, a essencialidade deve ser analisada à luz do princípio constitucional da dignidade humana, classificando os bens e serviços numa escala que varia de indispensáveis a absolutamente supérfluos para uma existência digna.

Em consequência, ao aplicar a essencialidade, parte-se daquilo que é essencial em função das necessidades básicas do indivíduo, tais como saúde, alimentação, vestuário, moradia, acrescentando, tudo aquilo que decorre do direito de cada um à dignidade humana. Em outras palavras, partindo-se daqueles produtos, mercadorias e serviços que compõem o mínimo existencial, os excedentes serão considerados menos essenciais ou supérfluos e, por conseguinte, passíveis de maior tributação.

Assim, considerando que a essencialidade pode ser graduada, o ônus tributário poderá não existir em sen- 
do o caso de tributação sobre bens e serviços absolutamente essenciais às necessidades primárias da população, ou ser fixada em escala ascendente, variando para mais na proporção da menor utilidade social dos bens e serviços. Portanto, a alíquota varia em razão inversa da utilidade do bem.

Estabelecer o que é mais ou menos essencial não é uma tarefa muito fácil. Porém, é possível determinar um critério consubstanciado num mínimo de produtos, mercadorias e serviços que atendam ao princípio da dignidade humana.

Dessa perspectiva, evidencia-se a relação existente entre a essencialidade e o mínimo existencial, na medida em que os produtos, mercadorias e serviços essenciais são aqueles indispensáveis à vida. Portanto, a noção daquilo que é essencial insere-se na ideia de mínimo existencial e, por conseguinte, no contexto da dignidade humana, na medida em que tal princípio abarca o direito de todos a um padrão de vida que assegure sua saúde, alimentação, trabalho, dentre outros direitos.

Contudo, não deve ser olvidado que o conceito daquilo que é essencial é mutável na dimensão do tempo e do espaço, em face da cultura, dos hábitos da sociedade, dos avanços tecnológicos. De modo que aquilo que hoje não é essencial à vida humana, poderá ser amanhã.

Nesse contexto, atualmente, produtos como remédios, gêneros alimentícios, materiais escolares e de construção, instrumentos de trabalho também são básicos, bem como peças básicas de vestuário, serviços de energia elétrica, telefonia, produtos como gás natural, petróleo e seus derivados, combustíveis, devem sofrer uma tributação mais branda ou até mesmo nenhuma, em razão de seu elevado nível de essencialidade.

Impõe-se referir, ainda, que a essencialidade, além de se apresentar sob a perspectiva do indivíduo, importando na exoneração da tributação incidente sobre o mínimo existencial, também se apresenta sob a perspectiva da coletividade, que considerando as necessidades coletivas, não tributa ou tributa reduzidamente os bens de consumo generalizado da população, como por exemplo, serviços de energia elétrica, de telecomunicação e de transporte.

À vista do que foi apresentado, percebe-se que a essencialidade consiste em algo mais do que uma mera linha diretiva para a tributação dos impostos indiretos. Trata-se de um princípio constitucional à tributação, aplicado pela seletividade das alíquotas dos impostos incidentes sobre o consumo.

Considerando que o princípio diz respeito a valores e fins, a essencialidade pode ser entendida como um princípio constitucional. Ela é um princípio na medida em que supõe a incorporação do valor justiça e atua como mecanismo de controle de tributação determinando 
um estado de coisas, a par de apresentar um conteúdo muito vago e indeterminado e estabelecer um critério valorativo a ser perquirido sem expor a conduta adequada.

A realização do princípio se faz mediante critérios de valoração da conjuntura econômica e social. Assim, o princípio da essencialidade se efetiva mediante ponderação axiológica.

$\mathrm{Na}$ aplicação do princípio da essencialidade, não há limites específicos, visto que inexistem critérios capazes de determinar aquilo que está ou não em conformidade com o princípio.

Ademais, o termo "princípio" denota a ideia de fonte ou origem de uma ação. Nesse sentido, pode-se dizer que o princípio da essencialidade tem como fonte ou origem a dignidade humana. O princípio da essencialidade seria uma forma de operacionalizar a igualdade tributária em atenção ao princípio fundamental da dignidade humana.

A essencialidade pode ser considerada um princípio na medida em que a sua exclusão do ordenamento jurídico implicará violação do princípio fundamental da dignidade. Para melhor compreensão do raciocínio, se a essencialidade for retirada do texto constitucional, não há como ser observado o princípio fundamental da dignidade humana na tributação do IPI e do ICMS.

Em que pese o princípio da essencialidade não oferecer demarcações claras e exatas para sua aplicação, ele tem por finalidade limitar a discricionariedade legislativa, uma vez que o legislador, ao fazer a eleição de produto, mercadorias ou serviços sobre os quais recairá o ônus tributário e em que medida, deverá considerar a essencialidade dos bens para a vida digna dos indivíduos.

\section{CONCLUSÕES}

À vista do exposto, podemos assentar que a distinção entre princípios e regras não é uma tarefa fácil. Todavia, pode-se considerar o princípio como aquela norma dotada de generalidade, enunciadora de valores ou de um mandamento sistêmico. Já a regra jurídica é aquela norma em cujo conteúdo se identifica prescrições específicas e concretas.

Um dos mais importantes critérios de aferição da igualdade é a capacidade contributiva das pessoas, uma vez que por meio dessa é possível verificar que alguns podem pagar tributos e outros podem pagar menos ou até não pagar.

Diante da noção de capacidade contributiva, nos impostos indiretos, particularmente no IPI e no ICMS, o esforço à sua materialização ocorre através do princípio da seletividade.

Perseguindo uma capacidade contributiva que corresponda à realidade e que não fique apenas no plano teórico, o mínimo existencial apresenta-se como um elemento para identificar a adequação da tributação. 
Pois parte das receitas do contribuinte se destina ao suprimento de suas necessidades básicas para garantir condições mínimas de existência digna e de sua família, visto que o direito ao mínimo existencial deriva do princípio fundamental da dignidade da pessoa humana.

Aos impostos indiretos, o legislador deve graduar a incidência tributária sobre mercadorias, produtos e serviços de acordo com sua essencialidade, de modo que quanto maior a importância social do bem ou serviço consumido, menor será a carga tributária incidente.

A essencialidade está relacionada com os produtos necessários às condições mínimas de vida e, quando

\section{REFERÊNCIAS}

ALEXY, Robert. Teoria delos derechos fundamentales. Madrid: Centro de Estudios Constitucionales, 2001.

ÁVILA, Humberto Bergmann. O princípio da isonomia em matéria tributária. In: TORRES, Heleno Taveira (Coord.). Tratado de direito constitucional tributário: estudos em homenagem a Paulo de Barros Carvalho. São Paulo: Saraiva, 2005. p. 407-439.

ÁVILA, Humberto Bergmann. Sistema constitucional tributário: de acordo com a Emenda Constitucional n. 42, de 19.12.2003. São Paulo: Saraiva, 2004a. observada, prestigia o princípio da dignidade da pessoa humana, contexto no qual o mínimo existencial está inserido. A essencialidade pode ser considerada um princípio constitucional à tributação, na medida em que a sua exclusão do ordenamento jurídico implicará violação do princípio fundamental da dignidade humana.

Dentre os modos possíveis de materialização do princípio da essencialidade, no Direito Tributário encontra-se a isenção e a seletividade de alíquotas.

Observa-se que o ICMS e o IPI dispõem do princípio da seletividade como instrumento de realização do princípio da essencialidade do produto, mercadoria e serviço.

ÁVILA, Humberto Bergmann. Teoria dos princípios da definição à aplicação dos princípios jurídicos. 4. ed. São Paulo: Malheiros, 2004b.

BECKER, Alfredo Augusto. Teoria geral do direito tributário. 2. ed. São Paulo: Lejus, 1972.

BALEEIRO, Aliomar de Andrade [1905-1978]. Limitações constitucionais ao poder de tributar. Atualizado por Misabel de Abreu Machado Derzi. 7. ed. rev. e ampl. Rio de Janeiro: Forense, 2005.

BRASIL. Constituição da República Federativa do Brasil: promulgada 
em 5 de outubro de 1988. 41. ed. São Paulo: Saraiva, 2008. 368 p. (Coleção Saraiva de Legislação). CALIENDO. Paulo. Princípios e regras: acerca do conflito normativo e suas aplicações práticas no direito tributário. Revista de Direito Tributário, São Paulo, n. 95, p. 124-151, 2006.

CANOTILHO, José Joaquim Gomes. Direito constitucional e teoria da Constituição. 7. ed. Coimbra: Almedina, 2003.

CARRAZA, Roque Antonio. ICMS. 11. ed. rev. e ampl. São Paulo: Malheiros, 2006.

DWORKIN, Ronald. Los derechos en serio. Barcelona: Planeta-De Agostini, 1993.

FREITAS, Juarez. A interpretação sistemática do direito. 4. ed. rev. e ampl. São Paulo: Malheiros, 2004. GRAU, Eros Roberto. Ensaio $e$ discurso sobre a interpretação/ aplicação do direito. 3. ed. São Paulo: Malheiros, 2005.

GUASTINI, Riccardo. Das fontes às normas. Tradução Edson Bini. São Paulo: Quartier Latin, 2005. MACHADO SEGUNDO, Hugo de Brito. A tributação da energia elétrica e a seletividade do ICMS. Revista Dialética de Direito Tributário, São Paulo, n. 62, p. 70-77, nov. 2000
MURPHY, Liam; NAGEL, Thomas. O mito da propriedade. Tradução Marcelo Brandão Cipolla. São Paulo: Martins Fontes, 2005.

SARLET, Ingo Wolfgang. Direitos fundamentais sociais, "mínimo existencial" e direito privado: breves notas sobre alguns aspectos da possível eficácia dos direitos sociais nas relações entre particulares. Porto Alegre: Escola da Magistratura do Tribunal Regional Federal da 4ª Região, 2007. (Caderno de Direito Administrativo, módulo 2). Também publicado em: SARMENTO, Daniel; GALDINO, Flávio. (Org.) Direitos fundamentais: estudos em homenagem ao professor Ricardo Lobo Torres. Rio de Janeiro: Renovar, 2006. p. 551-602.

TILBERY, Henry. O conceito de essencialidade como critério de tributação. In: NOGUEIRA, Ruy Barbosa (Coord.). Estudos tributários em homenagem à memória de Rubens Gomes de Souza. São Paulo: Resenha Tributária, 1974. p. 309-348.

TORRES, Ricardo Lobo. Tratado de direito constitucional financeiro e tributário: valores e princípios constitucionais tributários. Rio de Janeiro: Renovar, 2005. v. 2. 